\title{
School-based hand washing using the 'tippy-tap' intervention in basic public schools Ghana: A Pre- and Post- Descriptive study in the Volta Region
}

\author{
Margaret Kweku' ${ }^{1}$, Hubert Amu ${ }^{2 *}$, Martin Adjuik ${ }^{1}$, Martin Amogre Ayanore ${ }^{3}$, Emmanuel Manu², Clement \\ $\mathrm{Narh}^{1}$, Fortress Yayra Aku${ }^{1}$, Joyce Komesuor ${ }^{2}$, Elvis Enowbeyang Tarkang ${ }^{2}$, John Owusu Gyapong ${ }^{4}$ \\ ${ }^{1}$ Department of Epidemiology and Biostatistics, School of Public Health, \\ University of Health and Allied Sciences, Ho \\ ${ }^{2}$ Department of Population and Behavioural Sciences, School of Public Health, \\ University of Health and Allied Sciences, Ho \\ ${ }^{3}$ Department of Family and Community Health, School of Public Health, \\ University of Health and Allied Sciences, Ho
}

${ }^{4}$ Office of the Vice Chancellor, University of Health and Allied Sciences, Ho, Volta Region, Ghana

DOI: 10.3396/ijic.v16i4.027.20

\begin{abstract}
We examined the availability and use of hand washing facilities in public basic schools before and after a 'tippytap' intervention project by the United Nations Children's Fund (UNICEF), Ghana in 2017. This descriptive study involved 29 primary and junior high schools selected from six districts in the Volta Region. A total of 316 and 346 pupils aged 9-20 years of age were interviewed in the baseline and end line surveys respectively. Descriptive and inferential statistics were used in estimating outcomes of interest. We found that the availability of hand washing stations increased from $61.1 \%$ in the baseline survey to $97.7 \%$ in the end line survey. Hand washing after defecation also improved from $68.7 \%$ to $82.7 \%$. Among pupils who washed their hands after urinating, there was an increase from $13.6 \%$ in the baseline to $30.6 \%$ in the end line survey. While $77.2 \%$ of the pupils washed their hands before eating in the baseline survey, this decreased to $74.3 \%$ in the end line survey. Pupils in the end line survey were also three times more likely to practise hand washing compared to the base line. We conclude that the tippy-tap intervention improved hand washing practices of pupils. The tippy-tap intervention could, therefore, be replicated in other regions of Ghana. In the Volta Region, however, there is a clear need for the installation of more tippy-taps and improved management of existing ones. Schools should also intensify education on hand washing especially before eating. These measures would ensure that Ghana accelerates progress towards meeting the Sustainable Development Goal Six targets of achieving universal and equitable access to adequate water, sanitation, and hygiene by the year 2030.
\end{abstract}

Keywords: Hand washing, schools, United Nations Children's Fund, Ghana

\section{Corresponding author:}

Hubert Amu

Department of Population and Behavioural Sciences, School of Public Health, University of Health and Allied

Sciences, Ho

Email address: hamu@uhas.edu.gh 


\section{Introduction}

Increasing equity in access to and use of safe water and sanitation facilities as well as improved hygiene practices will reduce child mortality, improve health and education outcomes, as well as contribute to the reduction of poverty and overall achievement of Sustainable Development Goal (SDG) 6 targets of achieving universal and equitable access to adequate water, sanitation, and hygiene by the year 2030. ${ }^{1}$ Water sanitation and hygiene (WASH) in schools does not only promote hygiene and increase access to quality education, but also supports national and local interventions to establish equitably sustainable access to safe water and basic sanitation services in schools. ${ }^{1}$

Poor WASH is the main cause of faecally-transmitted infections (FTIs), including cholera and other diarrhoeal diseases, which remain the second leading cause of morbidity and mortality among children under-five ${ }^{2}$ and the leading cause of death in subSaharan Africa. ${ }^{34}$ Hand-washing with soap (HWS) falls under the third pillar of WASH and is the single most important means of preventing the spread of infections. ${ }^{5}$ It reduces the risk of diarrhoea by $50 \%{ }^{6}$ and acute respiratory tract infections (ARTI) by 20\%.7 Although HWS has proven to be an effective mechanism in averting the transmission of faeco-oral and other infectious diseases in school children, ${ }^{8-16}$ the practice in developing countries including Ghana is very low. A 2015 school-based study conducted in the Mion District for instance found that $85 \%$ of schools had no hand-washing facility mounted on their premises and that only $30 \%$ of the schools had a functional water point close to the school premises. ${ }^{17}$ To forestall this situation, there is an ongoing campaign to boost awareness of the importance of having designated places for hand washing with running water and soap; Ghana's Public-Private Partnership (PPP) for HWS. ${ }^{17,18,19}$

In this study, we examined the distribution of installed tippy-taps, the availability of hand washing facilities in public basic schools and the proportion of pupils practicing hand washing. Our study is essential in that any hand washing intervention in schools should include sustainable, safe water supply points, handwashing stands, and sanitation facilities. An effective and efficiently implemented hand washing in schools programme will lead to healthier pupils who will positively influence hygiene practices in their homes and the wider community, change their current hygiene behaviour and continue better hygiene practices in the future.

\section{The Tippy-Tap Project}

In 2017, UNICEF implemented a tippy-tap campaign through education and the construction of the tippy-tap as an affordable, sustainable, fun, and appropriate low-cost technology in all basic schools in the 25 districts of the Volta Region of Ghana. The project involved installation of portable hand washing stations (made up of water and soap) at vantage points in schools. The tippy-tap is designed in such a way that water is filled in a small gallon plastic container which is hung across a stick and pupils use their foot to cause water to flow from the container by stepping on another stick which connects to the gallon from the ground. The water used is mainly clean water from nearby pipes in the community which is refilled into the container when it gets finished. The refilling of the container is monitored by the teachers to prevent contamination of the water. The project was to support the government of Ghana in addressing

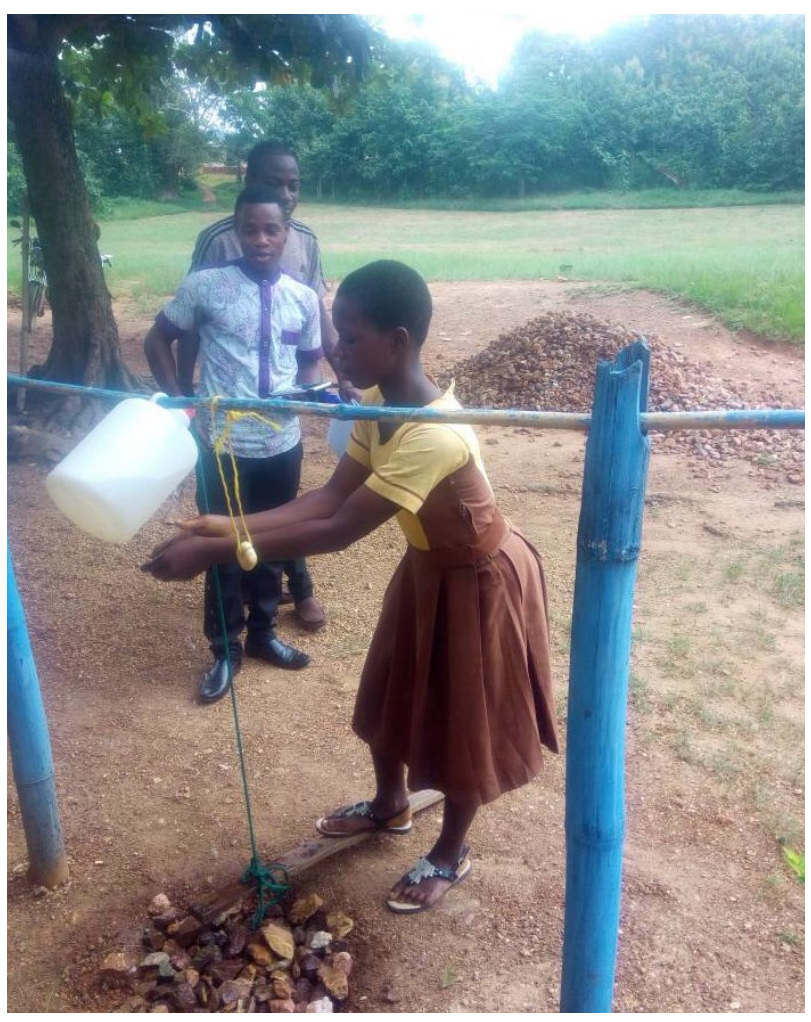

Figure 1. A pupil using an installed tippy-tap 
poor hygiene practices in schools and in fulfilment of the rights to water and sanitation by UN Resolution A/RES/64/292, as well as assisting countries to meet the UN Sustainable Development Goal Six.

Prior to implementation of the tippy-tap intervention, the baseline survey of our study was conducted in February 2017. Three months after the tippy-taps were installed (July 2017) by UNICEF, the end line survey was then conducted. Specifically, the baseline survey was conducted in, the tippy-tap intervention was implemented immediately after the base line (March-April) and, the end line survey was conducted. Figure 1 shows a pupil using an installed tippy-tap.

\section{Materials and Methods}

Setting

The study was a pre- (base line) and post- (end line) intervention study conducted in the Volta Region of Ghana. The region is located along the Southern half of the Eastern border of Ghana, which it shares with the Republic of Togo. ${ }^{19}$ It also shares boundaries to the west with Greater Accra, Eastern and Brong Ahafo Regions, to the north with the Northern Region, and has the Gulf of Guinea to the south. The Region's total land area is 20,570 square kilometres, representing $8.7 \%$ of the total land area of Ghana. ${ }^{20}$ The Region is divided into 25 administrative municipal/district assemblies headed by municipal/district chief executives. As of 2017, the population of the Region according to the Ghana Statistical Service based on projections from the 2010 Population and Housing Census figures was $2,491,293 .{ }^{21}$ Out of this, males constituted 1,223,722.

\section{Design and procedures}

A descriptive cross-sectional design was adopted in conducting this study. The study population comprised pupils in public basic schools in the Volta Region. It was, however, conducted in 29 primary and junior high schools (JHS) in the Region. For the selection of schools, the Region was divided into three zones: Northern, Middle, and Southern. Two districts were then randomly selected for each zone using the lottery method. With this, the names of all districts in each of the zones were written on pieces of paper, folded and placed in a bowl. The bowl was then shaken thoroughly and the first district selected.
This procedure was repeated for each zone to obtain the second district. After the selection of the districts, the lottery method was again adopted in selecting five schools from each district. Stratification was used to ensure that each class, from Primary 4 to JHS 3, was fairly represented in the selection. Thus, "Yes" or "No" was written on pieces of paper, folded and mixed in a container for males and females separately in each class. Each pupil in a group (male/female) was then asked to pick one paper. Those who picked "yes" were then included in the survey.

Using the formulae by Scheaffer ${ }^{22}$ and based on $65 \%$ coverage of access to water ${ }^{23}$ with a precision of $5 \%$, the sample size was calculated to be 350 at the 95\% confidence level since we needed a minimum sample of size of 360 pupils. Two data collection tools which were purposely developed for the project were used for the assessments during both surveys. A semi-structured questionnaire was administered to the schools and an observation checklist was also used for each selected school. Appendix I contains details of the instruments. The questionnaires were administered through face-to-face interviews. The observation checklist guided the research team as to what to look out for when they entered a school to observe the tippy-taps. They were for instance expected to observe if the taps were located at the most suitable places, those who were using them and their conditions at the time of the visit. Suitable places in this regard refer to vantage points such as in front of the classroom, beside the urinal/toilet etc. within the schools' environs where the tippy taps could be situated.

On reaching a school, the field team sought permission to take a transect walk to see if tippy-taps were available in the schools and if they were accessible; and where necessary, were being correctly used. In addition, they observed the condition of the tippytaps. Data collection for the study was done by visiting the sites where the taps were installed to observe if they were still there. Pupils (male and female) from public basic schools in Primary 4 to JHS 3 who were present in school at the time of the survey and whose parents/guardians consented to their participation in the study were included. Pupils in Primary 1 to 3 and those who were not in school or their parents/ 
guardians did not give consent were thus excluded from the study. Prior to the main data collection, the questionnaire was pretested in the Hohoe Municipality. This afforded the team the opportunity to have practical experience with administration of the study tool. Cronbach alpha analysis conducted also showed that the instrument appropriately measured its expected constructs ((Cronbach alpha $=0.70)$.

\section{Ethical issues}

Ethical clearance was obtained from the Ghana Health Service Ethics Review Committee (GHS-ERC) (No:GHS-ERC 06/11/16). Permission was sought from the regional and district directors of the Ghana Education Service in the Region. The study provided an information sheet to participants and parents/ guardians, informed consent form (ICF), and an assent form for all the various data collection tools. The informed consent process was initiated a week prior to the data collection. There was engagement with parents/guardians of pupils on the informed consent process. These included training of School Health Education Programme (SHEP) coordinators in the selected schools on the informed consent process as they assisted the research team to the homes of pupils for their parental or guardian informed consent. Detailed ethical issues in the study such as benefits, risks, confidentiality and privacy, data storage and usage, conflict of interest etc. were included in the ICFs and given to participants and parents/guardians. The ICF and an assent form for all the various data collection tools were also included.

\section{Analysis}

Data management involved designing screens/data entry templates on tablets for data entry, validation, cleaning and making it available in a format that can be used for analysis. The data manager (DM) checked

Table I. Socio-demographic characteristics of the pupils in both surveys

\begin{tabular}{|c|c|c|c|c|c|c|c|c|}
\hline \multirow[t]{2}{*}{ Variable } & \multicolumn{4}{|c|}{ Base line survey } & \multicolumn{4}{|c|}{ End line survey } \\
\hline & $\begin{array}{c}\text { Northern } \\
\text { zone } \\
{[\mathrm{N}=96]} \\
\mathrm{n}(\%)\end{array}$ & $\begin{array}{c}\text { Middle } \\
\text { zone } \\
{[\mathrm{N}=111]} \\
\mathrm{n}(\%)\end{array}$ & $\begin{array}{c}\text { Southern } \\
\text { zone } \\
{[N=109]} \\
n(\%)\end{array}$ & $\begin{array}{c}\text { Total } \\
{[\mathrm{N}=316]} \\
\mathrm{n}(\%)\end{array}$ & $\begin{array}{c}\text { Northern } \\
\text { zone } \\
{[\mathrm{N}=120]} \\
\mathrm{n}(\%)\end{array}$ & $\begin{array}{c}\text { Middle } \\
\text { zone } \\
{[\mathrm{N}=123]} \\
\mathrm{n}(\%)\end{array}$ & $\begin{array}{c}\text { Southern } \\
\text { zone } \\
{[\mathrm{N}=103]} \\
\mathrm{n}(\%)\end{array}$ & $\begin{array}{c}\text { Total } \\
{\left[\begin{array}{c}\mathrm{N}=346] \\
\mathrm{n}(\%)\end{array}\right.}\end{array}$ \\
\hline \multicolumn{9}{|l|}{ Sex } \\
\hline Female & $47(49.0)$ & $56(50.5)$ & $53(48.6)$ & $\begin{array}{c}156 \\
(49.4)\end{array}$ & $59(49.2)$ & $66(53.7)$ & $52(50.5)$ & $\begin{array}{c}177 \\
(51.2)\end{array}$ \\
\hline Male & $49(51.0)$ & $55(49.5)$ & $56(51.4)$ & $\begin{array}{c}160 \\
(50.6)\end{array}$ & $61(50.8)$ & $57(46.3)$ & $51(49.5)$ & $\begin{array}{c}169 \\
(48.8)\end{array}$ \\
\hline \multicolumn{9}{|c|}{ Age (years) } \\
\hline $9-12$ & 32 (33.3) & $33(29.7)$ & $30(27.5)$ & $95(30.2)$ & $43(35.8)$ & $32(26.0)$ & $25(24.3)$ & $\begin{array}{c}100 \\
(28.9)\end{array}$ \\
\hline $13-16$ & $52(54.1)$ & $68(61.3)$ & $61(56.0)$ & $\begin{array}{c}181 \\
(57.1) \\
\end{array}$ & $57(47.5)$ & $80(65.1)$ & $67(65.0)$ & $\begin{array}{c}204 \\
(59.0) \\
\end{array}$ \\
\hline $17-20$ & $12(12.6)$ & $10(9.01)$ & $18(16.5)$ & $40(12.7)$ & $20(16.7)$ & $11(8.9)$ & $11(10.7)$ & $42(12.1)$ \\
\hline \multicolumn{9}{|l|}{ Grade } \\
\hline Primary & $50(52.1)$ & $50(45.1)$ & $60(55.1)$ & $\begin{array}{c}160 \\
(50.6)\end{array}$ & 65 (54.2) & $54(43.9)$ & $58(56.3)$ & $\begin{array}{c}177 \\
(51.2)\end{array}$ \\
\hline JHS & $46(47.9)$ & $61(54.9)$ & $49(44.9)$ & $\begin{array}{c}156 \\
(49.4)\end{array}$ & 55 (45.8) & 69 (56.1) & 45 (43.7) & $\begin{array}{c}169 \\
(48.8)\end{array}$ \\
\hline
\end{tabular}


the data as entry was synchronized on a daily basis and ran descriptive analysis to do plausibility checks and any inconsistencies that were not detected during data entry. The DM ensured that the data were cleaned for analysis before finally transferring into any software format for statistical analysis. Five percent quality control paper-based interviews were conducted for selected schools. Also, data collectors cross-checked all data collected and made the necessary corrections before leaving the field.

Table II. Number of tippy-taps constructed in the 29 schools visited

\begin{tabular}{|c|c|c|c|c|}
\hline Zone & School & $\begin{array}{r}\text { Number of } \\
\text { pupils }\end{array}$ & $\begin{array}{l}\text { Number of } \\
\text { tippy-taps }\end{array}$ & $\begin{array}{l}\text { Number } \\
\text { of pupils/ } \\
\text { tippy- tap }\end{array}$ \\
\hline \multirow{10}{*}{ Northern } & Bodada DA JHS & 39 & 3 & 13 \\
\hline & Damanko D.A Primary & 328 & 2 & 164 \\
\hline & Ep JHS Jasikan & 70 & 8 & 9 \\
\hline & Jasikan Kings Presby School & 390 & 4 & 97 \\
\hline & Kofi Nyi Ecg Primary School & 168 & 0 & 0 \\
\hline & New Ayoma RC Basic School & 484 & 7 & 69 \\
\hline & Ogyiri D/A Primary & 343 & 5 & 69 \\
\hline & Pibila DA JHS & 36 & 7 & 5 \\
\hline & Sibi Jato Kparekpare DA Primary & 215 & 6 & 36 \\
\hline & Abolove/Nolopi DA JHS & 58 & 3 & 19 \\
\hline \multirow{10}{*}{ Middle } & Kpando Aziave Basic School & 147 & 9 & 16 \\
\hline & Dzolo Gbogame E.P Primary School & 254 & 6 & 42 \\
\hline & Dzolo Gbogame EP JHS & 82 & 8 & 10 \\
\hline & Dzolo Kpuita DA JHS & 54 & 8 & 7 \\
\hline & Dzolo Kpuita Ep Primary & 214 & 8 & 27 \\
\hline & Kpando Agbenorxoe M/A JHS & 47 & 5 & 9 \\
\hline & Kpando Anglican Basic School & 363 & 8 & 45 \\
\hline & Kpando Torkor RC Basic & 377 & 5 & 75 \\
\hline & Sovie Kudzra R.C Primary School & 206 & 8 & 26 \\
\hline & St Peter's Claver RC JHS & 526 & 15 & 35 \\
\hline \multirow{9}{*}{ Southern } & Akome Gbota D/A Junior High School & 37 & 4 & 9 \\
\hline & Akplorwotorkor RC Basic & 173 & 7 & 25 \\
\hline & Avegorme Baptist Primary School & 203 & 6 & 33 \\
\hline & Dalive Torzikpota DA Primary School & 169 & 6 & 28 \\
\hline & Dorkloame D/A JHS & 57 & 6 & 9 \\
\hline & Galo Sota DA JHS & 49 & 5 & 10 \\
\hline & Hatorgodo Rc Basic School & 736 & 12 & 61 \\
\hline & Tegbi Agbedrafor MA Basic School & 549 & 7 & 78 \\
\hline & Woe Salvation Army Basic School & 800 & 4 & 200 \\
\hline
\end{tabular}


Data analyses were done using Stata 14.1 (StataCorp. 2015. Stata Statistical Software: Release 14. College Station, TX: StataCorp LP.). Frequencies, percentages, means, and chi-square statistics were used in measuring outcomes of interest. Binary logistic regression was used to determine the association between the dependent variable (hand washing practice) and zone, school grade, and sex of pupil. Poisson regression was also used to determine the incidence of tippy-taps installed in schools against the zone and whether they were installed in the base line survey or the end line survey. The variable "good hand washing practice" was a composite variable created from the three binary variables: hand washing before eating, hand washing after defecation and hand washing after urinating. All statistical analyses were considered significant at $p<0.05$.

\section{Results}

\section{Socio-demographic characteristics of pupils}

Table I presents the socio-demographic characteristics of the pupils. In the base line survey, $49.4 \%$ were females while in the end line survey they constituted $51.2 \%$. The majority of pupils recruited for the base line (57.1\%) and end line (59\%) surveys were 13-16 years old. In the base line survey, $50.6 \%$ of the pupils were in primary school and this remained fairly the same $(51.2 \%)$ in the end line survey.

\section{Number of tippy-taps constructed in the schools}

There were 7,174 pupils in the schools visited with 182 tippy-taps installed, giving an average of 39 pupils per tippy-tap per school (Table II). The average number of tippy-taps installed per school by zone was 4.5 (ranging from 0-8) in the Northern zone, 8 (ranging from 5-15) in the Middle zone and 6 (ranging from 4-12) in the Southern zone.

\section{Hand washing practices of pupils in the surveys}

From Table III, $61.1 \%$ of the pupils said hand washing stations were available in their schools during the base line survey and in the end line survey, this increased to $97.7 \%\left(x^{2}=139, p<0.001\right)$. In terms of hand washing after defecation, $68.7 \%$ of the pupils reported doing so in the base line survey whereas $82.7 \%$ of them in the end line survey indicated washing their hands after defecation $\left(\chi^{2}=18.4\right.$, $p<0.001)$. In the base line survey, $13.7 \%$ stated they washed their hands after urinating while in the end line survey, $30.6 \%$ did so $\left(x^{2}=27.5, p<0.001\right)$. While $77.2 \%$ of the pupils reported washing their hands before eating in the base line survey, this decreased to $74.3 \%$ in the end line survey $\left(x^{2}=0.8, p=0.379\right)$ (Table III).

Table IV presents the results of the logistic regression of good hand washing practice by zone, survey, sex and grade (class). There was a significant association between the two surveys. Pupils in the end line survey were three times more likely to perform good hand washing practices as compared to those in the base line survey $(\mathrm{OR}=3.16,95 \% \mathrm{Cl}=2.01-4.96, \mathrm{p}<0.001]$. There was no significant association between good hand washing practices and zone, sex and grade.

Table III. Self-reported hand washing practices by pupils in the two surveys

\begin{tabular}{lrrrr} 
& $\begin{array}{r}\text { Base-line survey } \\
{[\mathrm{N}=316]} \\
\mathrm{n}(\%)\end{array}$ & $\begin{array}{r}\text { End-line survey } \\
{[\mathrm{N}=346]} \\
\mathrm{n}(\%)\end{array}$ & $\begin{array}{c}\text { Chi-square } \\
\text { Variable }\end{array}$ & $\mathrm{p}$-value \\
\hline Available wash station & $193(61.1)$ & $338(97.7)$ & 139 & $<0.001$ \\
\hline Hand washing before eating & $244(77.2)$ & $257(74.3)$ & 0.8 & 0.379 \\
\hline Hand washing after defecating & $216(68.7)$ & $286(82.7)$ & 18.4 & $<0.001$ \\
\hline Hand washing after playing & $101(32.1)$ & $113(32.7)$ & 0.03 & 0.87 \\
\hline Hand washing after urinating & $43(13.6)$ & $106(30.6)$ & 27.5 & $<0.001$ \\
\hline Hand washing by friends & $276(87.3)$ & $322(93.1)$ & 6.2 & 0.013
\end{tabular}

Source: Field work, 2017 
Males were also less likely to practise hand washing than their female counterparts.

Table $V$ presents a Poisson regression of the number of tippy-taps installed by zones in both surveys. The results indicate that in the end line survey, the number of tippy installed were ten times more than in the base line survey and this was statistically significant [IRR=10.7 (95\% Cl 6.51,17.6), $\mathrm{p}<0.001$ ]. There was no significant association between the tippy-taps installed by zone (Table V).

\section{Discussion}

Our study involved a base line survey before intervention and an end line survey after intervention in public basic schools, looking at the availability of tippy-taps in schools and hand washing practices of pupils. The Centres of Disease Control and Prevention indicate that keeping hands clean through improved hand hygiene is one of the most important steps that can be taken to avoid getting sick and spreading germs to others. ${ }^{23}$ If clean running water is not accessible as is common in many parts of the world, or soap and water are unavailable, it is appropriate to use an alcohol-based hand sanitizer that contains at least $60 \%$ alcohol to clean hands. ${ }^{5}$ In order to improve hand washing with soap in schools, hand washing facilities must be available and easily accessible.

In our study, we realised that hand washing stations increased from $61.1 \%$ in the base line survey to $97.7 \%$ in the end line survey. We also found that the number of tippy-taps available were ten times more in the end line survey as compared to the base line survey. Our finding regarding the proportion of handwashing stations in the end line survey is higher than the 83\% reported in the end line survey by Contzen et al. ${ }^{24}$ in southern Ethiopia. The increase in the number of handwashing stations in our end line survey is could, therefore, be due to the "the tippy-tap project" intervention which was implemented after the base line survey was conducted.

Our study also revealed that there was an overall significant improvement in good hand washing practices from $9.1 \%$ in the base line survey to $23.1 \%$ in the end line survey $(p<0.001)$. These findings are similar to what was reported in Bangladesh by Rabbi and Dey ${ }^{25}$ who found that hand washing practice increased significantly from $8 \%$ at base line to $22 \%$ at end line $(p<0.01)$.

Table IV. Logistic regression of "good hand washing practice" on zone, survey, sex and grade

\begin{tabular}{|c|c|c|c|c|c|}
\hline Variables & $\mathrm{n} / \mathrm{N}(\%)$ & Odds Ratio & $\mathrm{p}$-value & & $95 \% \mathrm{Cl}$ \\
\hline \multicolumn{6}{|l|}{ Zone } \\
\hline Middle & $39 / 237(16.5)$ & Ref & & & \\
\hline Northern & $30 / 226(13.3)$ & 0.75 & 0.28 & 0.44 & 1.27 \\
\hline Southern & $42 / 218(19.3)$ & 1.24 & 0.404 & 0.75 & 2.04 \\
\hline \multicolumn{6}{|l|}{ Survey } \\
\hline Base line & $31 / 339(9.1)$ & Ref & & & \\
\hline End line & $80 / 346(23.1)$ & 3.16 & $<0.001$ & 2.01 & 4.96 \\
\hline \multicolumn{6}{|l|}{ Sex } \\
\hline Female & $60 / 337$ (17.8) & Ref & & & \\
\hline Male & 49/333 (14.7) & 0.82 & 0.351 & 0.536 & 1.25 \\
\hline \multicolumn{6}{|l|}{ Grade } \\
\hline Primary & $60 / 350(17.1)$ & Ref & & & \\
\hline JHS & $51 / 334(15.3)$ & 0.91 & 0.652 & 0.594 & 1.39 \\
\hline
\end{tabular}

Source: Field work, 2017 
This study found that the proportion of pupils practicing hand washing significantly improved in the end line survey compared to the base line survey. Hand washing after defecating also improved from $68.7 \%$ in the base line survey to $82.7 \%(p<0.001)$ in the end line survey. This finding agrees to a similar study among school children by Shrestha and Angolkar ${ }^{26}$ in south India. In their study, the authors found a significant increase in hand washing practice after defecation from $52.1 \%$ in the base line survey to $78.1 \%$ in the end line survey $(p<0.05)$. In Bangladesh, Rabbi and Dey ${ }^{25}$ also found that hand washing practice after defecation increased from $72 \%$ at base line to $88 \%$ at end line $(p<0.01)$.

In our study, even though the proportion of pupils who washed their hands before eating in the end line survey was lower than in the base line survey, the difference was not statistically significant. This finding differs from what was reported in India where they found a significant improvement in hand washing before meal $(p<0.01) .{ }^{26}$ The decline in hand washing before eating in the post-intervention survey could be due to the fact that during the implementation of the tippy-tap intervention, education on hand washing focused on other aspects such as washing hands after defecating, to the demerit of hand washing before eating.

Hand washing by friends can serve as an example for others. In our study, hand washing by friends also improved from $87.3 \%$ in the pre-intervention to $93.1 \%$ in the post-intervention. Our study also found significant improvement in hand washing after urinating between the base line and end line surveys. The pupils were three times more likely to practise hand washing in the end line survey compared to the base line survey. This is probably due to the fact that the hand washing facilities were made available and accessible to the pupils by the tippy-tap project.

Despite the important findings made in the present study, a possible limitation has to do with recall bias from the pupils on practices relating to hand washing. Also, our regression analyses did not account for unobserved heterogeneity. We also did not assess the correlation between hand hygiene practices and ARTI and gastrointestinal illness after installation of tippy-tap. This could have improved our findings considerably.

This survey has demonstrated that the tippy-tap intervention actually had a positive influence on the hand washing practices of pupils as there was an increase in coverage between the base line and end line surveys for variables such as having a place for washing hands, washing hands after urinating, washing hands after defecation and hand washing by friends. Schools in the Middle zone had more tippytaps constructed than the other zones at the end line. Availability of hand washing facilities increases hand washing practices by three times.

\section{Recommendations}

The tippy-tap project could be replicated by UNICEF in other regions of the country due to the overall

Table V. Poisson regression of tippy-tap incidence at base line and end line surveys

\begin{tabular}{lrrrrr} 
Variable & No of tippy-taps & Rate ratio & $\mathrm{p}$-value & & $95 \% \mathrm{Cl}$ \\
\hline $\begin{array}{l}\text { Survey } \\
\text { Base line survey }\end{array}$ & 17 & Ref & & & \\
\hline End line survey & 182 & 10.71 & $<0.001$ & 6.51 & 17.60 \\
\hline $\begin{array}{l}\text { Zone } \\
\text { Middle }\end{array}$ & 82 & Ref & & & \\
\hline Northern & 56 & 0.91 & 0.589 & 0.65 & 1.28 \\
\hline Southern & 61 & 0.99 & 0.961 & 0.71 & 1.38
\end{tabular}

Source: Field work, 2017 
success recorded in terms of the hand washing practices of school pupils. In the Volta Region where the current study was conducted, there is a clear need for more installation and management of tippy-taps in some of the schools especially those in the Northern and Southern zones. The schools should also intensify education on hand washing with particular focus on topics such as hand washing before eating.

\section{List of Abbreviations}

CDC: Centres for Disease Control and Prevention, DANIDA: Danish International Development Agency, DM: Data Manager, EMIS: Education Management Information System, FTI: Faecally Transmitted Infections, HWS: Hand Washing With Soap, JHS: Junior High School, NTDs: Neglected Tropical Diseases, PPP: Public Private Partnership, SDG: Sustainable Development Goals, SHEP: School Health Education Programme, UNICEF: United Nations Children Fund, WASH: Water, Sanitation, and Hygiene, WHO: World Health Organization.

\section{Availability of data and materials}

The data used to support the findings of this study are available within the manuscript

\section{Competing interests}

The authors declare that they have no competing interests.

\section{Funding}

Funding for the tippy-tap project was provided by UNICEF, Ghana. Funding was, however, not received for this publication.

\section{Acknowledgements}

The tippy-tap project was undertaken with support and involvement of a number of stakeholders. These included the Ghana Education Service (Constant Dzakpasu - Volta Regional Office), the Ghana Health Service, the Community Water and Sanitation Agency (CWSA), the Environmental Health Services Department (EHSD), the school teachers of the basic schools visited, food vendors, parents and community members, basic school pupils, UNICEF Ghana (eg. Marcia Halm - Independent WASH and Public Health Consultant; Paa Kwesi Woode - UNICEF Ghana; Denis Collins Businge - UNICEF Ghana; and Leticia
Ackun - UNICEF Ghana), Unilever Ghana, and the University of Health and Allied Science (UHAS). UHAS was involved in both the base line and end line surveys. UNICEF Ghana worked closely with the Ghana Education Service in the Volta Region to carry out education and installation of the tippy-taps in basic schools in the Region. Financial support for carrying out the surveys was provided by UNICEF Ghana. We are grateful to the staff of the School of Public Health, University of Health and Allied Sciences. We are also grateful to the staff of the schools included in the survey. We would also like to thank the interviewers, the parents of the children, and the pupils who participated in the study.

\section{Authors' contributions}

$\mathrm{MK}$ and $\mathrm{CN}$ conceived the study. MK, MA, and HA did the data analysis and wrote the methods section. MK, HA, MA, MAA, EM, FYA, JK, ET and JG were responsible for the initial draft of the manuscript. All authors reviewed and approved the final version of the manuscript.

\section{Conflict of interest}

The authors have declared that they have no conflict of interest regarding this manuscript

\section{References}

1. United Nations Children's Fund (UNICEF). UNICEF Water, Sanitation and Hygiene Strategy 2006-2015. New York: UNICEF; 2005.

2. Lim SS, Vos T, Flaxman AD, et al. A comparative risk assessment of burden of disease and injury attributable to 67 risk factors and risk factor clusters in 21 regions, 19902010: a systematic analysis for the Global Burden of Disease Study 2010. Lancet 2012; 380(9859): 2224-2260. https://doi. org/10.1016/S0140-6736(12)61766-8

3. Prüss-Ustün A, Bartram J, Clasen T, et al. Burden of disease from inadequate water, sanitation and hygiene in low-and middle-income settings: a retrospective analysis of data from 145 countries. Trop Med Int Health 2014; 19(8): 894-905. https://doi.org/10.1111/tmi.12329

4. Mills JE, Cumming O. The impact of water, sanitation and hygiene on key health and social outcomes: A review of the evidence New York: UNICEF; 2016.

5. Centers for Disease Control and Prevention (CDC). When and How to Wash Your Hands. 2016. Centers for Disease Control and Prevention, Atlanta, GA. https://www.cdc.gov/ handwashing/when-how-handwashing.html

6. Curtis V, Cairncross S. Effect of washing hands with soap on diarrhoea risk in the community: A systematic review. Lancet Infect Dis 2003; 3: 275-281. https://doi.org/10.1016/S14733099(03)00606-6 
7. United Nations Children's Fund (UNICEF). A Report Card on Water and Sanitation. UNICEF: New York; 2006. http://www. unicef.org/wash/index_36021.html.

8. Guinan M. McGuckin M. Ali Y. The effect of a comprehensive hand washing program on absenteeism in elementary schools. Am J Infect Control 2002; 30: 217-220. https://doi. org/10.1067/mic.2002.120366

9. Luby SP, Halder AK, Tronchet C, Akhter S, Bhuiya A, Johnston RB. Household characteristics associated with handwashing with soap in rural Bangladesh. Am J Trop Med Hyg 2009; 81(5): 882-887. https://doi.org/10.4269/ajtmh.2009.09-0031

10. Thanh Xuan LT, Hoat LN. Handwashing among schoolchildren in an ethnically diverse population in northern rural Vietnam. Global Health Action 2013; 6(1): 18869. https://doi. org/10.3402/gha.v6i0.18869

11. Setyautami T, Sermsri S, Chompikul J. Proper hand washing practices among elementary school students in Selat subdistrict, Indonesia. Journal of Public Health and Development 2012; 10: 3-20.

12. Scott B, Curtis V, Rabie T. Protecting children from diarrhoea and acute respiratory infections: the role of hand washing promotion in water and sanitation programmes. WHO Reg Health Forum 2003; 7: 42-47.

13. Lopez-Quintero C, Freeman P, Neumark Y. Hand washing among school children in Bogota, Colombia. Am J Public Health 2009; 99: 94-101. https://doi.org/10.2105/ AJPH.2007.129759

14. Steiner-Asiedu M, Van-Ess SE, Papoe M, Setorgio J, Asiedu DK, Anderson AK. Hand washing practices among school children in Ghana. Current Research Journal of Social Sciences 2011; 3: 293-300.

15. Pinfold JV. Faecal contamination of water and fingertip-rinses as a method for evaluating the effect of low-cost water supply and sanitation activities on faeco-oral disease transmission. I. A case study in rural North-east Thailand. Epidemiol Infect 1990; 105: 363-375. https://doi.org/10.1017/ S0950268800047956

16. Ogunsola F, Balogun M, Aigbefo $S$, et al. Perception and practice of hand washing in Kuramo Community, Lagos, Nigeria. Int J Infect Control 2013; 9(1). https://doi. org/10.3396/ijic.v9i1.006.13
17. Ghana Statistical Service (GSS), Ghana Health Service (GHS), ICF International. Ghana Demographic and Health Survey 2014: Key indicators report. Maryland: GSS, GHS, and ICF International; 2015.

18. United Nations Children's Fund (UNICEF), Ghana. Study on hand washing with soap (HWWS) in 20 selected basic schools in the Mion District in the northern region of Ghana, Accra: UNICEF; 2016.

19. Ministry of Local Government and Rural Development, Ghana. National Environmental Sanitation Strategy and Action Plan NESSAP. National Environmental Sanitation Strategy and Action Plan (NESSAP) 2010 - 2015. Accra: Ministry of Local Government and Rural Development; 2010.

20. Ghana Statistical Service (GSS). 2010 population and housing census: Regional analytical report: Volta Region. Accra: GSS; 2013.

21. Ghana Statistical Service (GSS). Projected population by district and sex, Volta Region, 2010, 2015-2020; 2018. http:// www.statsghana.gov.gh/docfiles/2010phc/Projections_ Districts_2015\%20to\%202020_submit.xlsx.

22. Scheaffer RL, Mendenhall W, Ott RL, Gerow KG. Elementary survey sampling. Boston, MA: Cengage Learning; 2011.

23. Centers for Disease Prevention and Control (CDC). Water, Sanitation \& Environmentally-related Hygiene: Keeping Hands Clean. Centers for Disease Control and Prevention, Atlanta, GA. https://www.cdc.gov/healthywater/hygiene/ hand/handwashing.html

24. Contzen N, Meili IH, Mosler HJ. Changing handwashing behaviour in southern Ethiopia: A longitudinal study on infrastructural and commitment interventions. Soc Sci Med 2015; 124: 103-114. https://doi.org/10.1016/j. socscimed.2014.11.006

25. Rabbi SE, Dey NC. Exploring the gap between hand washing knowledge and practices in Bangladesh: A cross-sectional comparative study. BMC Public Health 2013; 13: 89. https:// doi.org/10.1186/1471-2458-13-89

26. Shrestha A, Angolkar M. Improving hand washing among school children: An educational intervention in South India. IOSR Journal of Dental and Medical Sciences 2015; 8: 81-85. 
Appendix A: Research Instruments

Questionnaire for School Pupils

1.0 Respondent Information

Question

Response

School Name

School District

1.1 Name of Respondent

1.2 Grade of respondent

1 - 6 for primary school

7- 8 for junior secondary school

1.3 Age of Respondent

1.4 Respondent Gender Male

Female

1.5 Date of Completion of Questionnaire DD/MM/YYYY

$\mathrm{DD} / \mathrm{MM} / \mathrm{YYYY}$

2.0 Knowledge and attitudes

Question

Response

2.1 When did you wash your hands yesterday?

Do not prompt for specific responses. Tick all those that apply

Before eating

After eating

After defecating/urinating

After playing

Before preparing food

Other (Specify)

2.2 What did you use to wash your hands?

Do not prompt for specific responses. Tick all those that apply

Water

Soap

Ash or other soap substitute

Disinfectant

Hand sanitizer

2.3 Why do you think you had to wash your hands?

They were dirty/To make them clean

To prevent sickness

To kill/clean germs

Parents/teacher instructed

Other (Specify)

2.4 When should you wash your hands?

Do not prompt for specific responses. Tick all those that apply

Before eating

After eating

After defecating/urinating

After playing

Before preparing food

Other (Specify) 
2.5 Do your friends in school wash their hands with soap and water Yes, all of them do when they should?

Do not prompt for specific responses. Tick all those that apply

Yes, most of them do

Some of them do

No, most of them don't

No, none of them do

2.5 Do your teachers teach/talk to you about hand washing in school? Yes, every week

Yes, at least once a term

Occasionally

Never

2.6 Is there always a specific place for you to wash your hands with Yes soap and water in school?

\begin{tabular}{ll}
2.7 Do you talk to your family at home about hand washing? & Yes \\
\hline
\end{tabular}

No

2.8 Have you had diarrhea* since the beginning of this term? Yes

${ }^{*}$ Diarrhea refers to loose bowels occurring at least three times within No

24 hours

\section{Observation Checklist}

1. Is there a functional water point available on the school compound? $\square$ Yes $\quad \square$ No If the answer is No:

Is there one accessible nearby? $\quad \square$ Yes $\square$ No

How far ways is the water source? ___ metres___ minutes

2. What is the source? $\square$ Piped water $\square$ Public tap or standpipe $\square$ Rain water $\square$ Tube well/ Bore hole $\quad \square$ Dug well $\square$ Spring $\quad \square$ Tanker truck

3. Are there hand washing facilities in the school? $\square$ Yes $\square$ No

4. How many hand washing facilities are there at the school?

5. What type of hand washing facilities are they? Tick all that apply

$\square$ Running water from a piped system (e.g. stand post or rainwater tank with a faucet)

$\square$ Veronica Bucket

$\square \quad$ Hand-poured water system (e.g. From bucket or bowl)

$\square$ Basin/bucket (hand washing is done in the water and not under running water)

- Tippy taps

$\square \quad$ Other (Specify)

6. How many of the school hand washing facilities currently (at time of visit) have:

\begin{tabular}{|c|c|c|c|c|c|c|}
\hline $\begin{array}{c}\text { Soap and } \\
\text { water }\end{array}$ & $\begin{array}{c}\text { Ash and } \\
\text { water }\end{array}$ & Just Water & Just Ash & Just Soap & $\begin{array}{c}\text { No Water, } \\
\text { Ash or Soap }\end{array}$ & Total \\
\hline & & & & & & \\
\hline
\end{tabular}


7. Where are the hand washing facilities located? Tick all that apply

$\square$ Close to toilets

口 Near Classrooms

$\square$ Food Vendors

$\square$ Anywhere within school grounds but not close to toilets, classroom or food vendors

$\square \quad$ Other (Specify)

8. How many hand washing facilities are functional? How many are not?

9. Are the hand washing facilities accessible to younger children? $\quad$ Yes $\quad \square$ No 